\title{
New locations: the virtual city
}

By Denise Maia Carter (Department of Sociology and Anthropology, University of Hull).

While raising questions about the position of the city in anthropological practice, much of the existing discourse has failed to acknowledge that there is a new kind of city out there, the virtual city. However, while the virtual city as a general analytical category may richly fulfil its function as a focal point for cultural meanings, this role may also be problematic, as revealed by my own fieldsite, Cybercity. ${ }^{1}$ Against a background that boasts the absence of a shared history of meaning, a new virtual community has been constructed in which human relationships appear to be organised more perfectly than in everyday life. Within this city, being a good citizen is organised around discourses of harmony and unity. This in turn leads to questions about the enforcement of community ideals articulated through the control of both images and texts within the virtual city. By addressing these issues, my aim is not to represent some new model of the city. Rather, it is an attempt to stimulate discussion that will allow a movement towards new models of cities that are central to anthropological practices.

'In relation to the writer the composer is always mad (and the writer can never be so, for he is condemned to meaning).' Barthes (1985:308)

During my ethnographic fieldwork I have come to understand that the physical reality of the environment is often less important than the social interactions that are played out between the individuals who live within it. The city is only one of many places where everyday human interactions are studied by anthropologists. In addition, anthropologists tend to justify their fieldsite as a context for their study of what is 'out there', using the fieldsite as no more than a frame within which a study of other cultures is articulated. As a result ethnographic fieldwork tends to occur in cities, rather than being of cities. As Low explains, 'anthropologists have been more concerned with everyday urban processes' (1996: 384) than with the position of the city in anthropology. If, as Low (1996: 384) suggests, there are many different ways to theorise cities, then in the course of my own fieldwork I have investigated a new kind of city on the Internet, the virtual city, one in which the everyday spaces of living and working are reproduced within technologically enabled landscapes of meaning. Cybercity is a very large city. The population on Friday $14^{\text {th }}$ November 2003 , numbered 1,051,437 citizens giving it a size comparable to the $389^{\text {th }}$ largest city in the world, and slightly smaller than Newcastle-on-Tyne in the UK (Brinkhoff, 2003). Its layout is similar to many other large cities in the world; among other amenities it has

\footnotetext{
${ }^{1}$ In order to maintain confidentiality I have changed the name of my fieldsite.
} 
a plaza, a beach, a café, a funfair, a post office, an employment office, a jail and suburbs where the residents live. It is also the city where I lived and worked for three years while engaging in ethnographic fieldwork, from September 1999 to March 2003. However, Cybercity is a city on the Internet, ${ }^{2}$ a social world that is no less real for being supported by Internet technologies, with residents drawn from countries all over the world, as is shown below. ${ }^{3}$

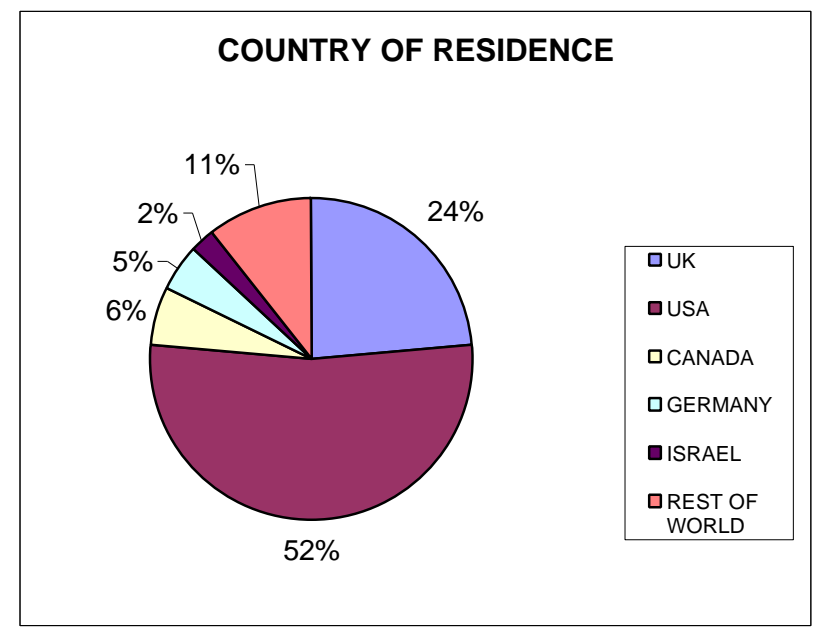

Fig 1: Chart showing geographical country of residence for Cybercity inhabitants, September 2003.

As you can see from this chart the inhabitants of Cybercity are physically and geographically isolated from one another. However, they come together within Cybercity and inhabit a social space that is produced through a combination of their subjective experience of Cybercity and their interaction with others who occupy the same place. Hence the 'place' that is Cybercity is produced when individual practices collide and become what Augé calls collective practices (1995: 51). It is important to remember that when exploring social phenomena online we often overlook the fact that the underlying technology is socially constructed (Schaap, 2002: 102). As Crang (1991: 2) explains, 'technologies are not self-contained entities that impact on the social', technologies are constituted by the social relations and discourses of everyday life because they are embedded within that life.

When investigating Cybercity these computer technologies can be divided into two basic types: the computer machine or hardware, and the programming or software. ${ }^{4}$ Physically separated, Cybercity inhabitants use their hardware or personal computers to access a set of social relationships that is constituted by everyday discursive social practices. They do this in an environment that is generated in cyberspace by software. All software is designed especially to conform to ideas about what the programmer wants it to do. The programming software behind Cybercity is specifically designed to simulate an environment of imaginary landscapes that allows people to interact socially in a meaningful way, by allowing people to 'be there' and to 'interact' with

\footnotetext{
${ }^{2}$ During the period of my ethnography Cybercity was free to enter, and was supported by a free software platform called Blaaxun that was originally developed for business conferencing.

${ }^{3}$ The data included in this pie chart is taken from demographic data collected during my own research in Cybercity. The rest of the world includes India, Brazil, China and France.

${ }^{4}$ In Cybercity the blaxxun software platform offered a community and 3D environment.
} 
others. Discursive ideas of 'community' drive the development of Cybercity software and also are included in descriptions about the place. In other words the founders (software designers, developers, etc) of this place on the Internet described it as a particular type of social space before it became one. They designed it to perform a particular function, that of a community platform, and then developed it to fulfil that function. The landscapes of Cybercity are based on other landscapes that people already inhabit. People's knowledge about how to inhabit these landscapes is grounded in their own common sense or subjective experience about how the 'real world' works. The following extract taken from the Cybercity information board is a statement of intent about the kind of place that Cybercity was designed to be:

Cybercity is a free, clean, safe community on the Internet... Citizens are actively involved in the social structure of the community and with each other, making Cybercity a true community that is created by its own residents. (extract taken from Cybercity information board)

My research indicates that these design aims have largely been met. Typical responses from my respondents suggest that Cybercity is perceived and reproduced as a place in similar ways to other arenas where time is invested in social interaction. For example, pandor ${ }^{5}$ one resident, says 'it is a great place to meet people'. Abbed, another resident, says 'it seems like a small town where everyone knows each other'. In addition, when residents were asked to describe Cybercity, community was a common theme, for instance in these three representative accounts; 'Cybercity is a community. I have a home there', 'Cybercity is a community place...on the net', and finally 'Cybercity is more than just a website - it is a community'. These comments echo Lefebvre's (1974:135) view of space as a social product. He argues that rather than space being a priori, a vacuum waiting to be filled, it is produced through social action. As such Cybercity provides a fertile environment for the deconstruction and interpretation of place and social space.

Cybercity is also a place that both facilitates and constrains ways of social interaction for its population through its control of the texts and images on display in the city. In Cybercity residents have their own private house. Each one of these houses is unique only in the personal touches that their owner bestows. Each resident gives their house a name on moving in and has optional links to their home pages, email address or the choice of adding a personal image that is visible when their house is visited. Not every resident adds these kinds of personal touches. For those that do there are rules and regulations regarding the posting of images and even web page addresses anywhere in Cybercity, for example no pornographic images or links to pornographic sites are allowed. In this case it is the ninth rule of the Cybercity Constitution (reproduced below) that is in force.

In building your dwellings in Cybercity, the above rules also apply. In other words you cannot furnish your spaces with textures, texts, objects or images that would be considered offensive, illegal, pornographic, and racist or that violate copyrights. (extract taken from Cybercity constitution)

Residents are hired to take responsibility for the public or private spaces. Residents apply for jobs at the Cybercity Employment Office. Informal interviews are conducted, and background checks are carried out prior to a more formal private

\footnotetext{
${ }^{5}$ People sometimes choose to use lowercase letters for names.
} 
interview. These do not necessarily result in a job offer, again reflecting 'real' life. Cybercity jobs are positions of power that vary according to the job's status. Like the real world, greater power equals greater responsibility and the reward of higher social status. These staff members regularly check private houses in the suburbs for content. They are granted access to parts of the software programming underpinning Cybercity that allows them to remove images and hyperlinks that do not conform to the constitutional aims reproduced above. There is a system of advancement with an inbuilt incentive scheme that rewards appointees with privileges and higher status. Experience points and Cybercity cash is earned simply by visiting Cybercity everyday. Different jobs and status are rewarded by different earning levels. Residents can use their Cybercity cash to buy goods and services in the mall and around the community. Those who are actively participating in the community by taking a job or function, such as Neighbourhood or Block Leaders, can earn even more credits.

In Cybercity the performance of everyday life is mediated through computer technology and enacted through the richness of text, the language of images, the writing of web pages and the construction of virtual identity. My preliminary analysis indicates that the two key issues of this enactment are harmony and unity. The first, harmony, is a reflection of the stated purpose in the city constitution that Cybercity facilitates the harmonious interchange of ideas and information (see below). The second, unity, reflects the conformity and consensus within the community that is enforced using strict self-policing techniques. For example any citizen who engages in offensive or inappropriate chat in the public spaces may be gagged, removed from the community for a certain length of time or exiled forever. In addition Cybercity sometimes seems to contain a doctrine for world citizenship:

\begin{abstract}
Cybercity includes a set of colonies where people are not discriminated against on the basis of personal beliefs, sex, age or race and a place where people are not attacked for these things. One intention of Cybercity is to provide an oasis for rationality, pleasant discourse and harmony, rather than tirades and insults against those who disagree with your views. (extract from The Cybercity Constitution, 2000)
\end{abstract}

Cybercity calls itself a city of the future and judges the history of the world thus far as lacking in harmony, unity and globality. It projects an optimistic and idealistic solution to these past deficiencies by providing a moral voice and supporting a doctrine for world citizenship on two levels.

Firstly it attracts citizens to a community based on common interests and goals such as those outlined in its constitution rather than on shared geography. As a result people inhabit Cybercity because they choose to. The city then transfers ownership of the community to all its citizens and encourages them to police themselves and enforce those community ideals stated in the constitution (see above). In addition, those citizens employed as staff have yet more powers to regulate and police Cybercity.

The community itself, in the interests of fostering positive community spirit, has decided what it will and won't accept. (extract from The Cybercity Constitution, 2000)

Secondly by dislocating real personal identity from the common referents of personal beliefs, sex, age or race, it encourages a virtual identity that is based on common values and is also one that essentially owns and reproduces the community identity. In effect, this reflects the ethos of a Utopia, where Cybercity is an imaginary community 
in which human relationships are organised more perfectly than in everyday life. Utopian interests are those that propose to create better conditions through reform (Mannheim, 1976). In Cybercity these reforms are purposefully built into the design, that is, of rationality, pleasant discourse and harmony, rather than tirades and insults against those who disagree with your views (see above). Yet discussion with citizens when they first moved to Cybercity suggested that this search for utopia was not foremost in their minds. Instead they were drawn by their search for an expanding circle of human relationships. Nevertheless, the citizens of Cybercity generally qualified this search with a reference to hopes of a world without social stigmatisation on the grounds of age or race etc. For example, Xanth, a community member says:

I chose to 'live' and work in Cybercity because I felt it is a great way to communicate with people I'd otherwise never meet and make friends all over the world, no matter what race, nationality, age, social status or sex they have. (excerpt from fieldnotes, October 2001)

Cybercub goes a step further and suggests that relationships in Cybercity might be organised more perfectly than in other places:

It's a world of people who come from a world of different lands, and join together as if we were all one of a kind. It's a place where there is no bashing of races, creeds or religions. People live together in a community of harmony and love. Much of what the real world could use a lot more of. (excerpt from fieldnotes, March 2002)

As suggested earlier, their community is based more on common interests and goals rather than on an accident of geography. As many people from many offline geographical lands migrate to Cybercity, their collective performance of community facilitates the transformation of little voices that in reality cannot be heard, into one voice in this virtual collectivity. Within this collectivity there seems to be a call for the adoption of ideals that provide a reasonable argument for perfect political and social conditions within Cybercity. This is supported by the implicit hope that this virtual voice will cause a powerful echo in the real world and perhaps change history.

The members of Cybercity resonate with the need to promote their key ideas of harmony and unity in the real world, seeing their virtual experiences as a panacea for the problems of humanity. Principal events in the real world, such as the bombing of the World Trade Centre initiated a plethora of texts and images to be uploaded to the houses of citizens. These images and texts contributed to reproducing the solidarity of both their performance of cyber community, and their ownership of a global conscience. This solidarity was achieved through the conformity of these images to the constraints imposed by the city ordinances. Although nationalist images of the American flag or ribbons like the one below were allowed, jingoistic sentiments were not. Instead, images and sentiments that positively reinforced the idea of a future where everyone would live in harmony were encouraged. 


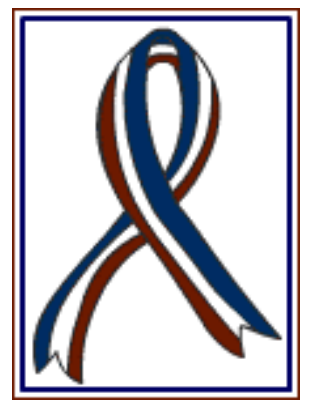

Fig 2: Image of an American ribbon placed on Cybercity houses in remembrance after $9 / 11$.

Non-conforming images and sentiments that would fuel violence and aggression against Arabs and Muslims in the US and elsewhere were actively policed and removed by those citizens hired for the purpose.

As I said earlier, each one of the inhabitants of Cybercity has their own place that is a representation of a house. This takes the form of a web page to which a single image may be uploaded. These images are not accompanied by an explanatory text, although text may be incorporated within the image. All of these images are on public show and anyone in Cybercity is free to visit another's home. According to Berger (1972), all visual representations or images convey a particular way of seeing by their creator. At the same time they are also subject to a more personal interpretation by their viewer, one which is based on the viewer's own culture and values. Accordingly, the creator and viewer will never achieve an absolute parity of meaning. However, this disparity will only be true if both the creator and the viewer remain free to construct their own narrative, and to imagine their own language of the image. In Cybercity neither the creator nor the viewer are completely free to negotiate meanings because the constitution forbids the use of texts or images that would be considered offensive, illegal, pornographic or racist. The choice of image that is placed on view is constrained by this community ideology, while at the same time, there is an assumption that the viewer is also similarly compelled by this same constraint. Thus the image becomes more than an image, it is a snapshot of meaning that has developed through the performance of the specific type of cybercommunity, and with which the inhabitants of Cybercity engage. Although it may appear that Cybercity inhabitants are severely constrained by their community ideology they are not prevented from uploading controversial images. Instead the opposite is true. Images are only removed when deemed offensive, thus providing spaces for individuals to engage in acts of resistance to conformity. In effect, what is being reproduced by the images that are left is not representative of the individual consciousness. Instead the images both capture and reproduce the authority of the collective consciousness (Berger 1972: 33). The viewer is not as free to construct their own narrative of the image as they might suppose, but is instead constrained by the solidarity of their everyday performance of cyber community or good citizenship. This is enforced by the control of 'community officials or others responsible for community activities' (City Rules, The Cybercity Constitution, 2000). Consequently, the residents of Cybercity are in Barthes' words 'condemned to meaning' (1985: 308). They are not free to produce meaning, rather, it is imposed by the community or city within which their social interactions are played out.

It is not surprising, that in this mainly text-based world, the written text is policed as ruthlessly as the images posted there. It may be that in the real world, people are forgiven their lapses in judgment based on any number of factors such as age, sex, 
race, creed or even illness. However, within Cybercity these social distinctions are not clearly defined and become dislocated from virtual identity. Citizens cannot tell a person's class, age or gender on first meeting. In addition, all textual intercourse both within Cybercity and within the email discussion groups associated with Cybercity are saved and recorded, and then any failure to conform to the community ideals is immediately recorded and reported. Whilst living and working in Cybercity I was myself involved in this recording and reporting practice. I and several other colleagues would share responsibility for 'sweeping' the homes in particular blocks and neighbourhoods in the suburbs. These sweeps were undertaken at weekly intervals. All images and texts were examined and those not conforming to the city's 'tyranny of words' (Chase 1938) were reported and later deleted by those invested with the authority to do so. This is how the conformity of images and texts produced after the World Trade Centre bombings was enforced, and non-conforming images and sentiments actively policed and removed.

The Virtual City then, in the case of Cybercity does not exist simply as a collective consciousness that reflects the common ideals and goals of a particular community. In fact the opposite seems to be the case, the virtual city represents a collective consciousness that is actively willing the transformation of everyday practices. Hence, on reflection, my original supposition that the virtual city merely provided a traditional context for engaging with my informants was challenged by the evidence that I have presented here. By organising and enforcing discourses of good citizenship around harmony and unity the virtual city itself became the pivotal component in my ethnography. Rather than engaging in ethnography in the city, it was necessary to think in terms of an ethnography of the city, since the nature of this city, Cybercity, was to manifestly construct the nature of its inhabitants. As a result the virtual city may be a theoretically useful category for further study into the symbolic organisation of online life, and of the interaction between online and offline life.

\section{References}

Augé, M. 1995. Non-places: introduction to anthropology of supermodernity. London. Verso.

Barthes, R. 1985. The responsibility of forms. New York: Hill and Wang.

Berger, John (1972) Ways of Seeing. London: Penguin.

Brinkhoff. 2003. The principal agglomerations of the world. Online at http://www.citypopulation.de/World.html

Chase, S. 1938. The tyranny of words. New York,: Harcourt, Brace \& World.

Crang M., Crang P. \& May, J. 1991. Virtual geographies: bodies, space and relations. London: Routledge.

Lefebvre, H. 1974. The production of space. In, Dear, M. \& Flusty, S. (Eds) 2002. The spaces of postmodernity: readings in human geography. Oxford.

Low, S.M. 1996. The anthropology of cities: imagining and theorizing the city. Annual Review of Anthropology. 25: 383-409.

Mannheim, K. 1976. Ideology and utopia London: Routledge \& Kegan Paul. 
Schaap, F. 2002. The words that took us there: ethnography in a virtual reality. Amsterdam: Askant.

\section{About the author}

Denise Carter is a temporary lecturer in social anthropology with particular interests in the transformative effects of the internet, and its increasing embeddedness in everyday lives. She is currently writing an ethnographic account of her three years living and working in a virtual community. This research, among other things, looked at friendship and community, new theories of space and place, the ways in which the challenges of online ethnography informs contemporary ethnographic practices and the writing of postmodern ethnography. For more information see Denise's own web site at http://www.denisecarter.net. 